\title{
Rechtsgeschichte
}

http://www.rg-rechtsgeschichte.de/rg4

$\operatorname{Rg} 2004$

$245-247$

Zitiervorschlag: Rechtsgeschichte Rg 4 (2004)

http://dx.doi.org/10.12946/rg04/245-247

\section{Cornelia Vismann}

\section{Recht künstlich}




\section{Recht künstlich*}

Eine Schlinge ist eine Schlinge. Zugleich ist sie ein markantes Symbol für den Tod durch Erhängen. Doch galt das Zeichen der Schlinge für diese grausame Tötungsart erst seit dem I8. Jahrhundert, als der spezifische Henkersknoten erfunden worden war. Zuvor wurden die zum Tode Verurteilten von einer Leiter aus mit einem Strick um den Hals an eine Leine gehängt und die Leiter dann weggestoßen. Entsprechend war das Symbol für die Strafe des Strangulierens eine Leiter. Der Kunstwissenschaftler Samuel Y. Edgerton, der in seinem wunderbaren Buch Pictures and Punishment von I985 die Bestrafungsszenen auf Bildern als rechtshistorische Quelle erschlossen hat, schreibt in dem Sammelband Kunst als Strafe über den Nutzen, den Künstler lange Zeit aus der Todesstrafe zogen. Die Getöteten und anschließend Sezierten boten im Mittelalter und der Renaissance das beste anatomische Anschauungsmaterial für die Maler menschlicher Körper. So hat beispielsweise auch das bekannte Werk von Andreas Vesalius De fabrica corporis humani von I 543 von den Hingerichteten profitiert.

Edgerton datiert das Ende der spektakulären und für die Künstler ergiebigen Hinrichtungen auf exakt den 30. Januar I649. An diesem Tag richtete man den König von England, Karl I., wie einen armen Schlucker hin. Cromwell ließ ihn auf einem viel zu niedrigen Holzbock köpfen und nahm ihm so die Möglichkeit eines Abgangs in Würde. Denn Geköpfte machen im Tod normalerweise eine bella figura, wie Edgerton weiß, während Strangulierte einen kümmerlichen Anblick bieten. Eine säkularisierte Form der Strafe des Hauptes wurde dann ohne großes Spektakel mittels der Guillotine exekutiert, die einen schmerzlosen, geradezu menschlichen Tod garantieren sollte. Für Edgerton stellt sie indes nur eine Station innerhalb der Reihe der Verschiebungen an Grausamkeit dar. Diese geht von den drastischen Todesarten durch Verbrennen oder Vierteilen allmählich über zu Formen psychologischer Folter, die »noch wesentlich abstoßender ist als ihr Vorfahr», die Guillotine.

Die These von den nicht endenden Grausamkeiten des Strafens erinnert an Foucault, der in Überwachen und Strafen die Erzählung von der fortschreitenden Humanisierung der Strafpraktiken bezweifelt. Sein Buch bildet den Referenzpunkt des Sammelbandes, wie es besonders deutlich wird in dem Beitrag des Philosophen Christoph Menke. Er kritisiert Foucaults These von der Subjektwerdung durch Disziplinierung als einseitig. Sie vernachlässige die Ästhetik. Hier werde der Kern des Subjekts sichtbar: das, was sich den Kontroll- und Strafmächten widersetze. Die Rettung eines widerständigen, ästhetischen Subjekts, wie Menke sie versucht, passt ganz in das Programm des Bandes, das darin besteht, mit Foucault, aber zugleich über ihn hinaus, emanzipatorische Potentiale der Ästhetik freizulegen. Die Kunst könne nach Vorstellung der Herausgeber etwas gegen die Logik der Strafe setzen, sie ermächtige Zuschauer zu richten und verwandle Täter in Künstler. »Die Ästhetisierung des Strafens drängt auf seine Abschaffung im Realen. Autonomie schließt Strafe aus: Wer die Verantwortung für seine Taten übernimmt, bedarf keiner Strafe mehr", heißt es am Ende des Vorworts.

Diese Ansicht von der Kunst als moralischer Anstalt muss man nicht teilen - nicht einmal alle

\footnotetext{
* Kunst als Strafe. Zur Ästhetik der Disziplinierung, hg. von GerTRUD Koch, Sylvia SASSE u. Ludger SChWARTe, München: Wilhelm Fink 2003, 229 S., ISBN 3-7705-377 I-8
} 
Beiträge des Bandes teilen sie - um gleichwohl mit großem Gewinn in dem Band zu lesen. Denn Kunst als Strafe verhandelt nicht etwa schlechte Kunst als eine Strafe für den Betrachter, wie man meinen könnte. Der Band thematisiert verschiedene Konstellationen, in denen Kunst und Strafe zueinander stehen. Dass die Ästhetik und die heikelste aller Rechtspraktiken, das Strafen, überhaupt etwas miteinander zu tun haben, ist nicht gerade selbstverständlich. Denn auf einen Gesetzesverstoß folgt in der Regel keine Kunst, sondern Strafe. Man kann freilich beides schlicht dadurch miteinander in Verbindung bringen, dass man das Strafen selbst als eine Kunst bezeichnet, als eine Kunst, die angemessene Art der Strafe zu finden, wie der Kriminologe Graeme Newman es in seinem Beitrag nahelegt. Abgesehen von seinem zweifelhaften Anliegen, das Prinzip der Reziprozität von Straftat und Strafe wiederzubeleben, erfasst sein Beitrag eigentlich keine der Facetten des Verhältnisses zwischen Kunst und Strafe, um die es dem Band geht. Anders die Theaterwissenschaftlerin Erika Fischer-Lichte: Sie betrachtet künstlerische Performances der Selbstverstümmelung als Akte der Selbstbestrafung. Der Slawist Georg Witte deutet in seinem Beitrag zu Moskauer Aktionskünstlern unter anderem die vielzitierte Sprühaktion Aleksandr Breners als eine Strafmaßnahme gegen die Kunst: Der Moskauer Künstler hatte ein Dollarzeichen auf ein Malevič-Gemälde gesprüht. Nach Witte setzt Brener seine Kunst (der Zerstörung eines bestehenden Kunstwerks) als Strafe gegen die Kunst ein.

Kunst und Strafe konvergieren nicht allein im ästhetischen Raum. Der Beitrag des Mitherausgebers Ludger Schwarte stellt die antike Tragödie als ästhetische Form des Strafens mit durchaus rechtlicher Relevanz dar. Auch die Filmwissenschaftlerin Gertrud Koch geht in ih- rem Beitrag von der Tragödie aus. Sie beschreibt filmische Antikenreferenzen, um die ambivalente Struktur zwischen Abscheu und Genießen beim Spektakel des Strafens zum Ausdruck zu bringen. Diese Janusköpfigkeit von Schaulust und Grausamkeit dekliniert die Anglistin Elisabeth Bronfen an Michael Powells i 960 entstandenem Film >Peeping Tom $>$ in allen Konstellationen des Blicks durch: vom perversen und mordenden Blick der Kamera bis zum strafenden Blick des Vaters. Dieser trifft die neugierigen, eitlen und selbstgenügsamen Frauen, die nichts anderes wollen, als beschaut zu werden, und er verschont seinesgleichen: Wissenschaftler, Regisseure, Produzenten. Allerdings kommen die »Verwalter des Voyeurismus « zumindest im Film nicht ungeschoren davon. Demontiert und bis auf die morschen Knochen der Rechtsordnung entlarvt steht die Polizei, "Stellvertreter des Gesetzes par excellence", da. Sie kommt, wie stets, zu spät und findet nur noch zwei Frauen: tot.

Man hat längst vergessen, dass das große Problem des Strafens einmal darin bestand, dass in jeder vollstreckten Strafe zugleich ein erneutes Verbrechen steckt, das seinerseits nach Sühne verlangt. Alois Hahn erinnert in seinem Beitrag zur Soziologie des Strafens an dieses Problem, das seiner Ansicht nach gelöst wurde, als der Staat das Strafen monopolisierte. Zweifellos stellt das Aufkommen der Zentralgewalt eine Zäsur in den Strafpraktiken dar. Eine ihrer Folgen, die auch Hahn hervorhebt, ist die Invisibilisierung der Vollstreckung. Wo Strafen nicht mehr als öffentliche Spektakel inszeniert werden, die Foucault in Überwachen und Strafen so plastisch beschrieben hat, da übernimmt das Gerichtsverfahren die Dramatisierung des Verbrechens. "Mit der Unsichtbarkeit der Strafe als Prozeß korrespondiert die Sichtbarkeit des Strafprozesses «, heißt es dazu bei Hahn. Und hier 
schließt sich der Kreis zur Tragödie, die einst antrat, das Verbrechen sichtbar zu machen. Jetzt obliegt dies dem Gericht, woraus sich dessen Verwandtschaft zum Theater herleitet.

Sylvia Sasse treibt die Verwandtschaft bis zur Verwechslung. Sie beschreibt die verschiedenen »Gerichtsspiele « im Russland der zwanziger und dreißiger Jahre: die stalinistischen Schauprozesse, die nachgespielten Schauprozesse und die Schauspiele kleinerer Vergehen. Nie ist in all diesen Konstellationen klar, wann ein Verbrechen inszeniert und wann die Theatralität eines Verbrechens inszeniert wird. Klar ist nur, dass es kein Vergnügen ist, wenn die Grenze zwischen Theater und Gericht verschwimmt. Fiktive Geständnisse ziehen reale Strafen nach sich, das ist die grausame Pointe politischer Schauprozesse. Die Zuschauer werden in diesen Strudel der Verwirrung hineingezogen, von dem man wegen Sylvia Sasses eindringlicher Art der Beschreibung auch als Leser nicht verschont bleibt: Wohnt man einem echten Theaterstück oder einem simulierten Gerichtsprozess bei? Beklatscht man einen als Schauspiel getarnten Strafprozess oder ein reales Verfahren gegen Schauspieler? Mit dieser Unentscheidbarkeit trieben russische Künstler in den 9oer Jahren nun ihrerseits ihr Spiel, indem sie das Vorzeichen innerhalb einer Aufführung/Verhandlung ständig vertauschten. Die Performer beendeten die Zweifel mit einer Frage über das Gericht, wodurch die Kunst der Inszenierung der Gerichtsverhandlung zum Gegenstand wurde. In dieser Metaverhandlung am Schluss der Performance blitzt - nicht zuletzt wegen der Performanz der Beschreibung Sylvia Sasses - als Vision auf, was im Vorwort postuliert wurde: die Vision eines Lebens, das auf der
Bühne verhandelt wird statt in Gerichtssälen und Gefängnissen.

Aus rechtshistorischer Sicht fällt an diesem und an den übrigen Beiträgen des Bandes vor allem der Reichtum an Aussagen über das Strafen auf. Man sieht, wie die Frage nach der Ästhetik der Strafe die Aussagemöglichkeiten gegenüber einer rein rechtshistorisch angelegten Forschung erweitert. Soziologen, Philosophen, Kunst- und Filmwissenschaftler, Slawisten und Anglisten haben etwas zum Thema Strafe zu sagen, wenn es unter der Prämisse der Kunst steht. Ist es da Zufall, dass ausgerechnet eine rechtshistorische Stimme in diesem Band fehlt? Die Rechtsgeschichte dient hier lediglich als Fundus für interdisziplinäre Forschungen zu einem juristischen Thema. Diese Rolle als stummer Dritter im Chor der benachbarten Disziplinen spielt die Rechtsgeschichte nicht nur in diesem Band. Auch sonst ist sie oft darauf reduziert zwangsläufig darauf reduziert, solange sie ihren Wissensschatz genau nach den Themen abfragt, zu denen er angelegt wurde, zumeist also juristischen (dogmatischen und ideengeschichtlichen) Themen. Es ist schon eine eigene Kunst, Fragen so $\mathrm{zu}$ formulieren, dass sie dem rechtshistorischen Wissen andere als die erwartbaren Aussagen über das Wann und Wie rechtlicher Institute und Institutionen abgewinnen. Aber diese Kunst oder techne ist machbar, wie der vorliegende Band zeigt. Indirekt enthält er eine Einladung an die Rechtsgeschichte, ihr Wissen mit dem zu verbinden, was sie traditionell weit von sich weist: den Bereich des Ästhetischen.

\section{Cornelia Vismann}

